\title{
Edítoríal.
}

\section{CONDITIONALISM AND CAUSALISM.}

M UCH of the antagonism that is often found to exist between the psychological standpoint and the organic standpoint in medicine arises from a lack of a mediatory symbol that makes both attitudes possible and valid. The tendency either to take an extremely psychological or an extremely material view of certain forms of sickness is partly due to the old conception of causalism in the etiology of disease. Medicine has been cursed by a narrow outlook, which seeks to find one specific and definite thing as a cause for a most complicated condition such as insanity or neurotic sickness. A garden that has turned into a profusion of weeds has done so because of many factors in conjunction. In other words, the old conception of causalism needs to be replaced by the more modern and broader one of conditionalism. In a recent paper Jung pleads for this replacement. "Tuberculosis", he remarks, "is no longer held to be caused by the specific bacillus. It owes its existence to a number of competitive causes. ... Undoubtedly a psychological cause can hardly ever produce insanity unless it is supported by some specific predisposition, but on the other hand a marked predisposition may exist where a psychosis may not arise so long as serious conflicts or emotional shocks are avoided." With the development of a standpoint of conditionalism in medicine more room is at once given to newer theories and a greater flexibility gained, so that co-operation is possible. To deny the psychological factor is as foolish as to deny the physiogenic factor in illness, but we tend to concentrate attention exclusively upon either one or the other. The integration of the nervous system, the integration of the endocrine system, or the integration of the conscious and unconscious realms of the human psyche, are not independent phenomena. Man is the supreme integration of every system, nervous, vascular, glandular, or psychological. The theories of compensation or co-ordination are not conceived of broadly enough as implicating all the systems, from the most psychological and subjective, down to the most physical and objective. For example, we do not think of studying the degenerative changes found in the endocrine system and the central nervous system in dementia præcox 
in conjunction with the psychological picture, because we are accustomed to think that the psychological changes and the physiological degeneration go hand in hand and are merely different aspects of the same thing. The view that changes in the physiological may be compensatory to the psychological stress and disharmony-that is, that they may be attempts at healing or compensation at the physiological level, and vice versa - is foreign to medical thought. It is only recently that the endocrine system has been seriously considered in this country. To those who are disinclined to believe in the possibility of a psychological factor behind many forms of sickness, the endocrine system comes as a vast relief. Every peculiarity of temperament and behaviour is attributed to some peculiarity in the endocrine pattern alone. In America, however, the recognition that the endocrine system is the link between the psychological and physical is general, and the idea that the psychological attitude can influence the endocrine system, which in turn can influence the body, as well as that the endocrine system can influence the psychological attitude, is not regarded as being beyond the realms of possibility. Such ideas give us a wide outlook, and lead to a conception of illness that is based more upon conditionalism than upon causalism. At the recent debate at the meeting of the British Medical Association at Cambridge upon psychogenesis in mental disease, many speakers gave it as their opinion that both a psychogenic and a physiogenic factor were to be considered.

We would plead, therefore, for the introduction of the conception of conditionalism into modern medical thought in this country, so that the various factors behind sickness may receive thorough consideration and not lead to antagonistic points of view. We are confident that once the full recognition of the importance of the psychological factor in some forms of illness is admitted, a reconciliation of the psychological and organic points of view in medicine would become possible through the conception of conditionalism. At present those who recognize the psychological factor are almost forced to be extremists, because of the necessity for defending their standpoint against those who ridicule the idea that certain mental and emotional attitudes towards life can ever interfere with perfect health. 